\title{
LA MOVILIDAD SALARIAL EN COLOMBIA, DESDE LA TEORÍA DE LA OMISIÓN LEGISLATIVA ${ }^{57}$
}

Wage mobility in Colombia, in light of the theory of legislative omission

Paola Stella Hernández Martelo 58

Fecha de recepción: 12 de octubre de 2017

Fecha de aceptación: 28 de noviembre de 2017

SUMARIO: 1. Introducción, Metodología; 2. Regulación de la movilidad salarial en Colombia; 3. Teoría de la omisión legislativa de Wessel; 4. La omisión legislativa en la movilidad salarial colombiana; 5. Conclusiones; 6. Referencias Bibliográficas.

57 Este artículo es parte de la tesis de maestría denominada "La movilidad salarial en Colombia, desde la teoría de la omisión legislativa", producto de la investigación jurídica realizada en la Maestría en Derecho de la Universidad de Cartagena. Recursos propios.

58 Abogada de la Universidad de Cartagena; Magíster en Derecho con énfasis en Investigación Jurídica de la Universidad de Cartagena; Especialista en Derecho Laboral y Relaciones Industriales de la Universidad Externado de Colombia; Docente de la Facultad de Ciencias Contables y Administrativas de la Corporación Universitaria Rafael Núñez Seccional Cartagena; Docente Fundación Colombo Internacional; Capacitadora del Centro de Arbitraje y Conciliación de la Cámara de Comercio de Cartagena; Conciliadora en Derecho y Equidad, adscrita a las listas oficiales de Conciliadores de la Cámara de Comercio de Cartagena; Asesora Jurídica y Abogada litigante. https://orcid.org/0000-0002-2003-9100 E-Mail: paohm3@gmail.com 
Paola Stella Hernández Martelo

\section{COMO SE CITA ESTE ARTÍCULO (APA 6)}

Hernández Martelo, Paola Stella (2018). La movilidad salarial en Colombia, desde la Teoría de la Omisión Legislativa. Revista Jurídica Mario Alario D’Filippo, Vol. X. №. 19, pág. 220-249

\section{RESUMEN}

El salario tiene una estrecha relación con la vida digna de un trabajador y de su núcleo familiar, pues permite la satisfacción de sus necesidades vitales.

Nótese que la falta del incremento salarial anual puede ser una causa injustificada de enriquecimiento del empleador, frente a un detrimento patrimonial del trabajador y se afecta con ello, el carácter conmutativo del contrato de trabajo. Esto, además, atenta contra la dignidad del trabajo, contradice el principio constitucional de movilidad salarial, disminuye los ingresos familiares, afecta la vida en condiciones dignas y la economía colombiana.

Este artículo científico es producto de un estudio sobre el principio constitucional de la movilidad salarial, el cual analiza si existe una omisión legislativa respecto de este principio, entendida omisión legislativa como un vacío legislativo que ignora injustificadamente los mandatos explícitos de la Constitución Política de 1991, omisión que afecta los derechos y garantías fundamentales.

\section{Palabras claves}

Principio, salario, movilidad salarial, omisión legislativa.

\section{ABSTRACT}

The salary has a close relationship with the life worthy of a worker and his family, because it allows the satisfaction of their vital needs.

Note that the lack of the annual salary increase can be an unjustified cause of enrichment of the employer, as opposed to a patrimonial detriment of the worker and the commutative nature of the work contract is affected. This also undermines the dignity of work, contradicts the constitutional principle of wage mobility, decreases family income, affects life in decent conditions and the Colombian economy.

This research paper is the product of a study on the constitutional principle of wage mobility, which analyzes whether there is a legislative omission with respect to this principle, understood as a legislative vacuum that unjustifiably ignores the explicit mandates of the 1991 Political Constitution, omission that affects fundamental rights and guarantees.

\section{Key Words}

Principle, salary, wage mobility, legislative omission 


\title{
1. INTRODUCCIÓN
}

La Constitución Política de 1991, señala que la facultad legislativa y la dirección general de la economía, están a cargo del Estado colombiano, quien, además, está obligado a brindar una especial protección al trabajo, el cual se ha reconocido como derecho fundamental. Este derecho, implica que las personas accedan a trabajos en condiciones dignas y justas, y que, a la vez, sean retribuidas con salarios dignos, que conserven en el tiempo su real poder adquisitivo y que garanticen por lo menos, el mínimo vital.

Asimismo, a nivel mundial se reconoce que es necesario un control de las tendencias salariales, lo cual implica el desarrollo de políticas públicas sostenibles, encaminadas a garantizar salarios que no se estanquen, es decir, que sean móviles y justos. Al respecto, menciona la OIT (2017) lo siguiente:

\begin{abstract}
"En los últimos años se ha reconocido cada vez más, la necesidad de controlar las tendencias de los salarios y de aplicar políticas salariales sostenibles, que atajen el estancamiento de estos, aumenten los niveles de remuneración de los millones de trabajadores y trabajadoras pobres del mundo, aseguren una distribución justa, reduzcan las excesivas desigualdades de los salarios y de la renta, y refuercen el consumo como pilar fundamental de una economía sostenible". (Organización Internacional del Trabajo [OIT], 2017, pág. 2)
\end{abstract}

Adviértase que Colombia tiene una economía inflacionaria, donde se presentan periódicos incrementos de los precios de los bienes, productos y servicios del mercado. Esto se pude concluir, luego de hacer un análisis de la tabla de variación porcentual del Índice de Precios al Consumidor (IPC), elaborada por el Departamento Administrativo Nacional de Estadística (DANE), del período comprendido de enero del año 2003 a mayo del año 2018. (DANE, 2018)

Con esto en mente, se resalta el hecho de que los bienes y servicios, se adquieren acorde al nivel de ingresos personales o familiares, siendo el salario, "la principal fuente de ingresos de los trabajadores" (Organización Internacional del Trabajo [OIT], s.f.)

Por ello, si se quiere conservar la calidad de vida de las familias colombianas, es necesario, entre otros aspectos, que el salario, mantenga su poder adquisitivo, es decir, que éste no pierda la capacidad de compra, lo cual se logra en gran medida, cuando el salario tiene aumentos de forma real.

De ahí surge el concepto de salario móvil o movilidad salarial, que implica que el salario debe ajustarse, es decir, actualizarse de forma real, periódica y permanente, teniendo en cuenta el comportamiento de los factores socioeconómicos que inciden en su determinación, como lo es la inflación y el PIB; así, se contrarresta la pérdida de su poder adquisitivo y entonces, podrá el 
salario conservar su valor en términos reales.

También la movilidad salarial, permite que no se afecte el mínimo vital de un trabajador, ni la equivalencia que debe tener el trabajo con el salario y con ello, se garantiza también, que se conserve el carácter sinalagmático y conmutativo de la relación laboral.

Respecto a la movilidad de la remuneración hay que decir, que existen normas jurídicas de rango nacional e internacional que regulan el incremento del salario mínimo y, además, hay normatividad interna sobre el reajuste del salario del sector público. Este tema también es abordado en Jurisprudencia de las Altas Cortes Colombianas.

Es por ello que la Corte Constitucional, ha definido la movilidad manifestando lo siguiente: "el principio constitucional de la movilidad de los salarios (art. 53), es aquel en virtud del cual el Estado debe velar por la conservación de la capacidad de compra de los trabajadores ante el impacto provocado por el fenómeno inflacionario". (C- 1433 , 2000, pág. 9)

Adviértase que es de suma importancia en materia laboral, el antes mencionado artículo 53 de la Constitución Política de 1991, pues en dicho artículo, se enuncian lo que se conoce como "principios mínimos fundamentales en materia de trabajo", dentro de los cuales se destaca, el de la remuneración mínima, vital y "móvil".

A propósito del salario móvil conocido también como movilidad salarial, no existe en Colombia un Código o una Ley, que indique la forma en que se debe realizar el ajuste o el incremento anual del salario de los sueldos superiores al salario mínimo legal mensual vigente, que devengan los trabajadores del sector privado o particular de la economía.

Tampoco el Congreso de la República de Colombia, ha cumplido lo dispuesto en el artículo 53 de la Constitución Política, referente a la expedición de un Estatuto del Trabajo que tenga en cuenta o desarrolle, los principios mínimos fundamentales en materia de trabajo, siendo uno de estos, el de la remuneración móvil o movilidad salarial.

De lo anterior se infiere que el Congreso colombiano, ha omitido la orden constitucional de legislar, de expedir un Estatuto del Trabajo. Esta conducta omisiva, es un claro ejemplo de lo que en teoría jurídica se denomina de las siguientes formas: omisión legislativa, omisión legislativa inconstitucional o inconstitucionalidad por omisión legislativa.

Por lo expuesto anteriormente, es significativa la importancia que tiene el concepto de omisión legislativa para el Estado colombiano, pues desde el año 1991, se adoptó el modelo de Estado social de derecho, que enuncia principios que requieren de desarrollo legislativo. 


\section{Metodología:}

A partir de este contexto, este artículo pretende explicar la movilidad salarial en el ordenamiento jurídico colombiano, desde la teoría de la omisión legislativa del jurista alemán Wessel.

Para cumplir este propósito, la metodología utilizada para el desarrollo de la investigación jurídica básica con un enfoque cualitativo y un método explicativo, se otorgó primacía a la sistematización de conceptos de carácter jurídico (normas jurídicas, principios, jurisprudencia y doctrina jurídica), para luego, explicar la movilidad salarial en el ordenamiento jurídico colombiano, desde la teoría de la omisión legislativa de Wessel. Se utilizó una orientación metodológica de orden teórico y el método sería teórico-deductivo y la hermenéutica jurídica fue esencial para el análisis jurisprudencial de sentencias referentes al tema objeto de estudio.

\section{Regulación de la movilidad salarial en Colombia}

El principio de movilidad salarial, se encuentra inmerso en el artículo 53 de la Constitución Política, pues este señala varios principios mínimos fundamentales, entre los cuales tenemos "la remuneración mínima, vital y móvil, proporcional a la cantidad y calidad de trabajo". (Const., 1991, art.53)

De lo anterior se colige que el principio mínimo fundamental antes mencionado, integra los siguientes aspectos:

1. La garantía de lo que se conoce como salario mínimo legal mensual vigente.

2. El respeto al mínimo vital del trabajador.

3. La movilidad del salario.

Respecto a este tercer y último aspecto, es decir, a la movilidad salarial, podemos afirmar que es "la capacidad de reajustar el salario estimando las fluctuaciones monetarias e intentando mantener su real poder adquisitivo". (Colombia, Corte Constitucional, 1999, Sentencia - SU 995, M.P. Gaviria Díaz. C.)

Asimismo, la Corte Constitucional se refiere jurisprudencialmente al concepto de movilidad del salario en la sentencia T-102 de 1995, con M.P. Alejandro Martínez, en la cual se destacan lo siguiente aspectos de la movilidad:

1) El artículo 53 de la Carta habla, de la remuneración MóVIL que no sólo comprende al salario mínimo sino a todos los salarios

2) El salario tiene que mantener su VALOR INTRINSECO, esto es, su poder adquisitivo. 
3) A nivel de las políticas macroeconómicas del Estado, este principio debe ser armonizado con las otras finalidades que la propia Constitución atribuye al Estado en materia económica, tales como:

3.1. La racionalización de la economía.

3.2. Dar pleno empleo a los recursos humanos.

3.3. Asegurar que todas las personas, en particular las de menores ingresos, tengan acceso efectivo a los bienes y servicios básicos (CP art. 334).

4) El mismo artículo 373 de la C.P. señala como obligación estatal, el velar por el mantenimiento de la capacidad adquisitiva de la moneda. Esa capacidad adquisitiva tiene su correlativo en la capacidad adquisitiva del salario.

5) Hay que lograr un valor en equidad.

6) La movilidad salarial es una lógica consecuencia de la naturaleza sinalagmática y conmutativa de la relación laboral, prueba de esto, es el reajuste automático de todas las pensiones.

7) Es absurdo que AL TRABAJADOR PASIVO (pensionado) se le reajuste su pensión y no se le reajuste su salario AL TRABAJADOR ACTIVO.

8) A pesar de que la cantidad y calidad del trabajo permanezcan inmodificables, si el salario se mantiene igual por más de un año, mientras el valor del bien producido aumenta nominalmente en razón de la depreciación de la moneda, se estaría enriqueciendo injustamente el empleador en detrimento del derecho que tiene el asalariado a recibir lo justo.

9) La falta de movilidad en los salarios sería incorrecta en un Estado, cuyas finalidades esenciales son garantizar la vigencia de un orden justo (Preámbulo y art. 2으.P.), para lo cual el Estado, tiene la facultad de dirigir la economía con el fin de asegurar que todas las personas, en particular los de menores ingresos, tengan acceso efectivo a los bienes y servicios básicos (art. 334 C.P.)

A Esto se añade que el Bloque de Constitucionalidad y Convencionalidad, introduce al ordenamiento jurídico colombiano nuevos catálogos de derechos, muchos de ellos provenientes del Derecho Internacional Humanitario y de Convenios de la OIT, que buscan como fin último, entre otros aspectos, la protección del trabajador, un trabajo en condiciones dignas y un salario digno y móvil.

Se resalta que normas internacionales ratificadas por Colombia, integran la Constitución Política de 1991, haciendo parte de la legislación interna del país, esto de conformidad a un criterio monista. 
En efecto, en varias sentencias de la Corte Constitucional se ha sostenido que, en materia laboral, el Bloque de Constitucionalidad, se encuentra conformado por los artículos $1^{\circ}$, 25, 26, 39, 53, 54, $55,56,57,64$ y 125 de la Constitución. También hace parte de este bloque, los tratados que sobre derechos humanos estén ratificados por Colombia, y los Convenios de la OIT. Respecto a estos últimos, actualmente hay 60 Convenios que están ratificados y 54 en vigor.

Se advierte que hace parte del Bloque de Constitucionalidad, el Pacto Internacional de Derechos Civiles y Políticos (1966), aprobado mediante la Ley 74 de 1968, Pacto que en su artículo 26, estipula el derecho a la igualdad y el derecho de todas las personas a una igual protección de ley sin ninguna discriminación.

También hace parte del Bloque, la Convención Americana sobre Derechos Humanos (1969), aprobada mediante la Ley 16 de 1972, que en su artículo 24, establece el derecho de las personas a la igualdad ante la ley y en su artículo 26, regula los derechos económicos sociales y culturales que deben tener un desarrollo progresivo en cada Estado, por vía legislativa u otros medios apropiados, teniendo en cuenta los recursos disponibles.

Conviene además resaltar, que Colombia se unió al Pacto Internacional de Derechos Económicos, Sociales y Culturales (1966), aprobado en Colombia mediante la Ley 74 de 1968. Su artículo 7 establece el derecho a toda persona al goce de condiciones de trabajo equitativa y satisfactoria que le aseguren en especial una remuneración que proporcione a todos los trabajadores como mínimo, varios aspectos de los cuales destaco los siguientes:

a) Salario equitativo e igual por trabajo de igual valor, sin distinciones de ninguna especie, con salario igual por trabajo igual, sin tratar distinto a las mujeres.

b) Condiciones de existencia dignas para ellos y sus familias.

c) Limitación razonable de horas y las variaciones periódicas pagadas

Asimismo, existen Convenios de la OIT ratificados y vigentes para Colombia sobre el salario, el trato igualitario y la consulta para la internacionalización de normas laborales. Se destacan los siguientes:

1) Convenio sobre los métodos para la fijación de salarios mínimos, 1928 (núm. 26), aprobado por la Ley 129 del 23 de noviembre de 1931, ratificado el 20 de junio de 1933.

2) Convenio sobre la protección del salario, 1949 (núm. 95), aprobado por la Ley 54 del 31 de octubre de 1962, ratificado el 7 junio 1963. Decreto de promulgación del convenio ratificado D. 1264 de 1997. 
3) Convenio sobre los métodos para la fijación de salarios mínimos (agricultura), 1951 (núm. 99), aprobado por la Ley 18 del 7 de junio de 1968.

4) Convenio sobre igualdad de remuneración, 1951 (núm. 100), aprobado por la Ley 54 del 31 de octubre de 1962. Decreto de promulgación del convenio ratificado D. 1262 de 1997.

5) Convenio sobre la discriminación (empleo y ocupación), 1958 (núm.111).

6) Convenio sobre la consulta tripartita para promover la aplicación de las normas internacionales del trabajo 1976 (núm. 144).

A propósito del Bloque de Constitucionalidad, en el artículo científico titulado, "La inconstitucionalidad por omisión. Necesidad de reconocimiento de la figura en Colombia como factor garantista de los derechos humanos", se resalta la necesidad de cumplir y desarrollar legislativamente lo dispuesto en la Constitución y en los tratados internacionales sobre Derechos Humanos ratificados por el Estado, para evitar que exista inconstitucionalidad por omisión legislativa y que, con ello, se comprometa el bloque de constitucionalidad. (Díaz Gamboa, 2009, pág. 163)

Además de las fuentes formales de derecho antes señaladas, tenemos la Recomendación número 135 de 1970 de la Organización Internacional del Trabajo (OIT), sobre fijación de Salarios Mínimos. Otras Recomendaciones relacionadas con el salario son la R85 de 1949 y la R180 de 1992.

Cabe resaltar que los Estados miembros de la OIT, deben procurar que lo dispuesto en los Convenios que han ratificado, se cumpla a cabalidad en su país, a la vez, deben reconocer la importancia de acatar también las Recomendaciones de la OIT, pues estas tienden a sugerir mejoras de las condiciones laborales de sus trabajadores, lo cual, en últimas, apuntará a la dignificación del trabajo y a la materialización de los principios de equidad y de justicia.

También existe la necesidad de hacer un desarrollo de los principios constitucionales, especialmente, aquellos relacionados con derechos fundamentales como el trabajo digno y el salario digno, principios comprendidos, además, en normas internacionales que están incorporadas dentro del Bloque de Constitucionalidad.

Araque, F. y Suárez, O. (2017, p. 110) manifiestan que el Estado colombiano busca garantizar y asegurar el ejercicio efectivo de los derechos de las personas con discapacidad mediante la adopción de medidas y políticas que cuenten con enfoque de inclusión, lo que permitirá eliminar toda forma de discriminación dada por una condición.

Respecto a la labor del legislador entorno al salario y su regulación en Colombia, existe el Código Sustantivo del Trabajo, regula aspectos como los elementos que integran el salario (art. 127 C.S.T. 
Subrogado. L. 50 de 1990, art. 14), su carácter de elemento esencial para todo vínculo contractual laboral (art. 23 C.S.T., Subrogado. L. 50 de 1990, art. 1), el salario mínimo (art. 145 C.S.T.), factores para fijar el salario mínimo (art. 146 C.S.T.), procedimiento de fijación del salario mínimo (art. 147 C.S.T. Modificado por la ley 50 de 1990, art. 19), el efecto jurídico de la fijación del salario mínimo (art. 148), entre otras disposiciones.

Sin embargo, en sentencias como la C-1549 de 2000, se plantea un evidente problema jurídico existente en el sistema jurídico colombiano, hay un trato diferencial respecto a la movilidad salarial de los trabajadores particulares que devengan más de un salario mínimo, pues el legislador ha omitido regular el reajuste automático del salario de estos trabajadores, cosa que no ocurre con aquellos que ganan un salario mínimo, pues estos cuentan con lo dispuesto en los artículos 146, 147 y 148 del Código Sustantivo del Trabajo y lo establecido en el art. 8 de la Ley 278 de 1996. A su vez, los empleados públicos cuentan entre otras disposiciones, con lo establecido en el artículo 4으 de la Ley 4a de 1992 y los altos funcionarios del Estado están amparados por lo dispuesto en el art. 264 de la Ley 5a de 1992.

\section{Teoría de la omisión legislativa de Wessel}

Las omisiones legislativas como se dijo anteriormente ocurren cuando existen mandatos contenidos en la Constitución Política para regular un asunto de especial interés y relevancia, que son inobservados por el legislador.

Respecto a lo anteriormente expuesto, existe una teoría jurídica formulada en 1952 por el jurista y juez alemán Wessel W., quien ha sido señalado como el pionero en la elaboración de la teoría de las omisiones legislativas, y su clasificación. (Sentencia Corte Constitucional , 1996)

En 1952, Wessel se convirtió en el primero en abordar la problemática de la "omisión legislativa inconstitucional o también conocida como inconstitucionalidad por omisión legislativa o simplemente, omisión legislativa". Al hacerlo resaltó que esta omisión, es causante de vulneraciones de ciertos derechos fundamentales.

Posteriormente, el término empezó a ser utilizado y analizado en distintas latitudes geográficas, adquiriendo una mayor envergadura y curiosidad en el ámbito jurídico a lo largo de la segunda mitad del Siglo XX y hasta la fecha. (Santos Flores, 2011).

Asimismo, esta teoría es utilizada y reconocida en nuestro ordenamiento jurídico. La Corte Constitucional (1996), en sentencia C-543 de 1996, hace un breve recuento de lo que la doctrina denominó "omisiones legislativas", señalando aspectos como su definición, clasificación y utilidad. A continuación, se destacan algunos de los aspectos señalados por la Corte en dicha sentencia: 
1) En la doctrina contemporánea, dentro de la concepción democrática ningún acto de las autoridades puede estar desprovisto de control, el cual se ejerce sobre las acciones del legislador y sus omisiones.

2) De acuerdo con la jurisprudencia y la doctrina, se entiende por omisión legislativa, la falta de actividad del legislador en el cumplimiento de la obligación de legislar que le impone expresamente el Constituyente.

3) Para que exista es requisito indispensable lo siguiente:

3.1. Que, en la Carta Política, exista una norma expresa que contemple el deber de expedir la ley que desarrolle las normas constitucionales.

3.2. Que el legislador incumpla el deber constitucional de legislar contenido en la norma expresa.

4) La omisión legislativa no se puede derivar de la ausencia de leyes por incumplimiento del Congreso del deber general de legislar.

5) Clases de omisiones legislativas:

5.1. Absoluta: No hay actuación del Estado. Ocurre cuando el legislador no produce ningún precepto encaminado a ejecutar el deber concreto que le ha impuesto la Constitución.

5.2. Relativa: Existe una actuación imperfecta o incompleta del legislador. Si bien el legislador ha expedido la ley, en ella solamente ha regulado algunas relaciones dejando por fuera otros supuestos análogos, con clara violación del principio de igualdad o de una condición esencial para armonizar con la ley. Los siguientes son los casos:

5.2.1. Cuando en cumplimiento del deber impuesto por la Constitución, favorece a ciertos grupos, perjudicando a otros.

5.2.2. Cuando en desarrollo de ese mismo deber, el legislador en forma expresa o tácita, excluye a un grupo de ciudadanos de los beneficios que otorga al resto.

5.2.3. Cuando el legislador al regular o construir una institución, omite una condición o un ingrediente que, de acuerdo con la Constitución, sería exigencia esencial para armonizar con ella. v.gr.: si al regular un procedimiento, se pretermite el derecho de defensa.

6) En Colombia, la Corte Constitucional no tiene competencia para conocer y resolver las omisiones legislativas absolutas por acción o demanda de inconstitucionalidad, pues la Corte no tiene competencia por no haber actuación, pues no hay un acto que pueda ser sujeto de control, pero sí tiene competencia cuando se trata de omisiones legislativas relativas. En estas últimas la Corte, mediante una sentencia, resuelve el Estado de Cosas Inconstitucionales. 


\section{La omisión legislativa en la movilidad salarial colombiana}

Se entiende por la omisión legislativa "la falta de desarrollo por parte del poder legislativo, durante un tiempo excesivamente largo, de aquellas normas constitucionales de obligatorio y concreto desarrollo, de forma tal, que impide su eficaz aplicación”. (Fernandez Rodriguez, 1998)

Así, por ejemplo, por más de dos décadas, el Congreso ha omitido el deber constitucional de legislar un Estatuto del Trabajo y a la vez, no se ha regulado el principio mínimo de remuneración móvil o movilidad salarial que debía estar contenido en dicho estatuto, tal como quedó plasmado en el artículo 53 de la Constitución Política de 1991, desconociéndose así, el principio de supremacía constitucional imperante en nuestro ordenamiento jurídico por el legislativo.

A pesar de haberse presentado varios proyectos de ley con este propósito, no se ha cumplido la obligación constitucional de legislar un Estatuto del Trabajo, situación que es advertida incluso jurisprudencialmente por las Altas Cortes colombianas.

Respecto a los proyectos de ley en mención, advierte Calderón Ortega (2014) lo siguiente:

"Luego de la expedición de la Constitución de 1991, fueron radicados en el Congreso de la República tres proyectos de ley con el propósito de dar cumplimiento a la orden expresa del artículo 53 de la Constitución nacional: los proyectos de ley No. 176 de 1992, 184 de 2006 y 42 de 2010. El primero además de pretender la expedición del Estatuto de Trabajo ordenado por la Carta Política, obedeció a una iniciativa popular apoyada en un millón de firmas; este, sin embargo, al igual que los otros proyectos, también fue archivado". (Calderón Ortega, 2014, pág. 76)

Cabe señalar ahora, que se han presentado varias demandas de inconstitucionalidad por omisión legislativa contra disposiciones que regulan los reajustes salariales del sector público y contra la norma que regula la fijación del salario mínimo en el sector particular.

Para resolver estas demandas de inconstitucionalidad, la Corte Constitucional fundamenta su competencia en el Decreto 2667 de 1991, y ha señalado como fundamento teórico la teoría de Wessel para explicar si tiene o no, competencia para resolver estas demandas de inconstitucionalidad, según se trate de omisiones legislativas relativas o absolutas.

Así, por ejemplo, en la sentencia C-1433 de 2000, se presentó una acción pública de inconstitucionalidad cuyo fin último fue el ajuste del salario a los servidores públicos. Allí se acumularon dos demandas contra la Ley 547 del 23 de diciembre de 1999, "por la cual se decretó el presupuesto de rentas y recursos de capital y Ley de Apropiaciones para la vigencia fiscal del 1o de enero al 31 de diciembre del 2000", en cuanto sus disposiciones, allí no se contempló las 
apropiaciones para cubrir durante la vigencia fiscal de 2000, el aumento que compensaría la pérdida del poder adquisitivo de los salarios de todos los servidores públicos.

Advierte la Corte Constitucional en la sentencia en cita, que ni el Gobierno, ni el Congreso, gozan de una facultad discrecional absoluta para definir a su voluntad, el incremento salarial anual de los servidores públicos, porque existen disposiciones constitucionales que limitan su actuación y le imponen unos criterios que son de rigurosa observancia, como son, entre otros, el reconocimiento del derecho a un trabajo en condiciones dignas y justas, de una remuneración mínima, vital y móvil y de su necesario ajuste por la inflación y el tratamiento equitativo, sin ningún tipo de discriminación.

También señaló la Corte Constitucional en la sentencia C-1433 de 2000, lo siguiente:

\begin{abstract}
"No es argumento suficiente para desconocer el ajuste del salario a los servidores públicos la situación fiscal del país pues ésta requiere de un manejo ajustado a los ordenamientos constitucionales y de éstos surge, con claridad meridiana, el deber constitucional para el Gobierno de conservar el valor real del salario, haciendo como lo determine la ley, los ajustes periódicos por inflación, así como los incrementos adicionales que se justifiquen, atendiendo los diferentes factores de orden político, social y económico." (Corte Constitucional, C-1433, 2000)
\end{abstract}

En definitiva, la Corte en la sentencia C-1433 de 2000, en lo relativo al artículo 2 de la ley 547 de 2000, declaró exequible la norma, salvo en cuanto la omisión del deber jurídico del ajuste salarial de los servidores públicos por el año 2000, en lo cual fue declarada INEXEQUIBLE. También, puso en conocimiento de su decisión al presidente de la República y al Congreso de la República, para que cumplieran con el deber jurídico omitido, antes de la expiración de la presente vigencia fiscal y, además, ordenó que se comunicara la decisión al Ministro de Hacienda y Crédito Público.

De lo anterior se colige que en la sentencia C-1433 de 2000, la Corte salvaguardó la movilidad salarial de estos servidores públicos.

Otro ejemplo, lo encontramos en la sentencia C- 911 de 2012, allí se resolvió una demanda de inconstitucionalidad contra el artículo 148 del Código Sustantivo del Trabajo, artículo que establece que la fijación del salario mínimo modifica automáticamente los contratos de trabajo en que se halla estipulado un salario inferior. El demandante adujo que existía una omisión legislativa relativa al establecer que la fijación del salario mínimo modifica automáticamente los contratos de trabajo en que se halla estipulado un salario igual o inferior al mínimo, pues omite cualquier referencia a quienes ganan un salario superior al mínimo, vulnerando con esto entre otros aspectos, el derecho a la igualdad. 
Señaló el actor en comento, que la política nacional incorporada en la regulación laboral, a juzgar por la norma demandada (artículo 148 de la Constitución Política), es contraria a normatividad constitucional e internacional aplicable, puesto que es el legislador a partir de su omisión, genera la discriminación en detrimento de quienes perciben una remuneración superior al salario mínimo legal.

Sin embargo, la Corte Constitucional, en la Sentencia C- 911 de 2012, que resolvió el caso anteriormente planteado, se apartó de lo expuesto por el demandante, pues consideró que el art. 148 del Código Sustantivo del Trabajo, es exequible, desestimó la existencia de una omisión legislativa relativa, argumentando que no existe vulneración al principio de igualdad respecto a las personas que devengan un mínimo frente a quienes tienen un salario mayor, pues señala que no son ni fáctica ni jurídicamente equiparables sus situaciones, lo que a juicio de la Corte, justifica que exista una regulación jurídica diferente entre ellos y que esto no quebranta el principio de igualdad, ni implica un tratamiento discriminatorio. Además, señaló que la exclusión tiene un principio de razón suficiente o de una justificación objetiva y razonable.

También indicó la Corte en la sentencia en comento que el derecho a la movilidad salarial, es decir, el derecho a mantener el poder adquisitivo del salario, no es un derecho absoluto en un Estado social y democrático, y que, por ello, no tiene que aplicarse de igual forma a los distintos valores que pueda tener la remuneración salarial de los trabajadores, situación que genera que no exista un deber de orden constitucional que obligue a adoptar una regulación como la señalada por el accionante.

De lo anterior se infiere que la Corte, en la sentencia C- 911 de 2012, tuvo en cuenta un criterio de comparación netamente relacionado con el nivel de ingresos, pero no tuvo en cuenta que todos los trabajadores tienen derecho a una regulación que les garantice trabajo en condiciones dignas y salarios justos y móviles, pues la movilidad, es un derecho de todo tipo de remuneración.

También consideró razonable la Corte, la especial protección de aquellos que ganan el mínimo y respecto a aquellos que devenguen más del salario mínimo, consideró que puede definir sus reajustes salariales la libre estipulación contractual y la libre iniciativa privada contenida en el artículo 333 de la Constitución Política.

Así las cosas, los únicos trabajadores a quienes el sistema jurídico no les está garantizando la eficacia de la norma constitucional que establece la movilidad salarial, son aquellos que devengan más del salario mínimo legal mensual vigente, pues sus homólogos en el sector público, si han sido amparados legal y jurisprudencialmente, e igualmente sucede con quienes devengan el salario mínimo. 
Adviértase que la Corte en la sentencia C- 911 de 2012, estuvo errada al afirmar que no hay un deber constitucional que obligue a regular el incremento de los salarios que superan el mínimo legal, pues existe una norma de rango constitucional, que enuncia como un principio mínimo fundamental, que toda REMUNERACIÓN debe ser móvil.

Nótese que la movilidad del salario es un principio que no es exclusivo del salario mínimo, así lo ha manifestado en reiteradas oportunidades la Corte Constitucional.

Ahora bien, el Estado debe tener en cuenta que existe una estrecha la relación entre la movilidad salarial; la dignidad del trabajo y del salario; la equidad; la justicia social y el bien común, principios que se deben ver reflejados en toda relación laboral, sin que se desconozca el hecho que existen algunas personas que pueden gozar de una protección especial por su condición económica particular.

Adviértase, además, que todo contrato laboral tiene un carácter conmutativo, por lo cual, se generan cargas y obligaciones que se deben entender equivalentes, situación que se desdibuja, cuando no se incrementa anualmente los salarios, pues el costo de vida sigue elevándose al igual que el precio de los bienes o servicios ofertados por el empleador y sin reajuste salarial, no ocurre lo mismo con el salario.

También hay que tener en cuenta que el mínimo vital, es un derecho fundamental que, según la Corte Constitucional, es concebido como "un derecho fundamental que tiene como característica ser cualitativo, por lo que supone que cada quien viva de acuerdo al estatus adquirido durante su vida". Las variaciones económicas pueden afectar el mínimo vital y, por ende, la vida digna (Sentencia T-199-16).

Se trae lo anterior a colación, para dejar sentado que si bien pueden existir condiciones económicas distintas acorde al nivel de ingresos de cada persona, cada ser humano tiene obligaciones de acuerdo al estatus que tiene durante su vida, esto determina el costo de las obligaciones tributarias, alimentarias, de vivienda, servicios, etc., y en la medida que su salario no se reajuste esto tendría como consecuencia un empobrecimiento y un consecuente detrimento de sus condiciones de vida que en el peor de los casos, podría llegar a afectar incluso su mínimo vital, la vida digna (derecho humano inherente a toda persona) y la dignidad del salario.

Nótese que, en el Preámbulo Constitucional, se señala que la Carta Política fue promulgada para asegurar la vida, el trabajo y la igualdad dentro de un marco jurídico que garantice un orden político, económico y social justo. 
Además de lo anterior, es deber constitucional del Estado garantizar a la población trabajo en condiciones dignas y justas, y una forma procurar esto es legislando sobre la movilidad salarial para que trabajo y salario mantengan su dignidad y se pueda proteger al trabajador, que es la parte más débil de la relación laboral.

Ciertamente el no hacer los reajustes salariales, amplía la desigualdad salarial y social existente en Colombia; genera disminución de las condiciones de vida de los trabajadores y sus familias; afecta el consumo en el mercado, la dignidad humana y del salario, el trato igualitario, la equidad, la justicia y el equilibrio que debe existir en las relaciones laborales.

Figura 1. Relación entre salario, movilidad salarial y vida digna.
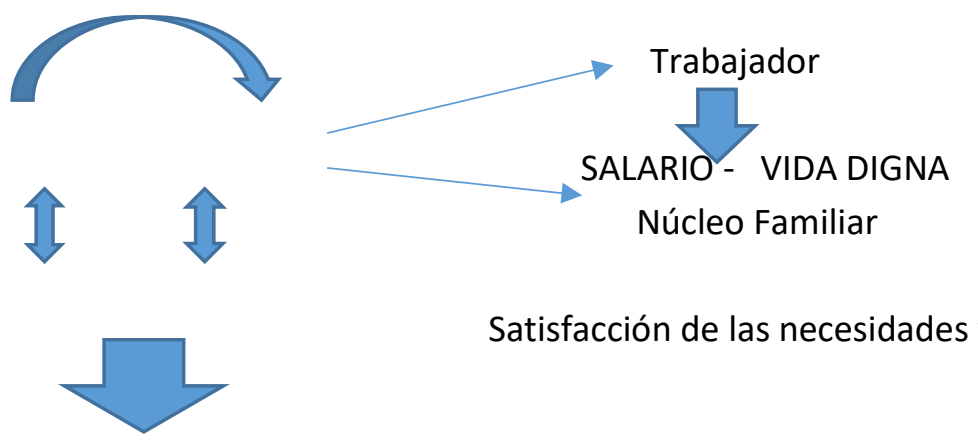

Satisfacción de las necesidades vitales

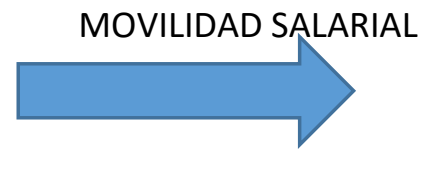

Capacidad de reajustar una

Asignación dada estimando:

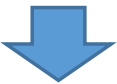

1. Fluctuaciones Económicas

2. Intentando mantener el poder adquisitivo real.

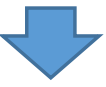

Para no perder la capacidad de compra de bienes y servicios y evitar un empobrecimiento del trabajador frente a un enriquecimiento injustificado del Empleador

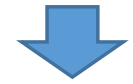

Todo acorde a los principios de Igualdad, Justicia Social, Equidad, Dignidad del Trabajo, Dignidad del Salario // Contrato Laboral Sinalagmático y Conmutativo.

Se resalta que la falta de regulación de los incrementos salariales de trabajadores del sector privado que devengan más de un salario mínimo ha generado que la Rama Judicial afirme que no tiene sustento legal para decidir en derecho las controversias relacionadas con la movilidad salarial de los trabajadores del sector privado de la economía que ganen más del salario mínimo. 
Y como no existe una ley que regule la movilidad del salario cuando éste es superior al mínimo, queda en potestad del empleador la posibilidad de incrementar anualmente estos salarios; esto a menos que el trabajador, negocie individual o colectivamente con el empleador, el incremento anual salarial; o que se resuelva este asunto mediante un Tribunal de Arbitramento.

Tampoco los Jueces de la Justicia Ordinaria, se atreven a tomar un principio general del derecho, o un principio constitucional o que opere en materia laboral, para resolver el problema jurídico consistente en la ausencia de incremento anual del salario de un trabajador del sector privado que devengue más de un salario mínimo. Generalmente cuando se plantean estos casos, los jueces argumentan que como no existe norma de derecho sustancial que regule el incremento no es un asunto de su competencia.

Así las cosas, los operadores judiciales de la Justicia Ordinaria Laboral, no toman los principios de remuneración móvil o movilidad salarial, de protección especial del trabajo en condiciones dignas, el de igual trabajo igual salario, el del mínimo vital, la vida en condiciones dignas, el de equidad, el de justicia social o el de solidaridad para llenar los vacíos legislativos y resolver los problemas jurídicos planteados en las demandas donde se reclama la movilidad salarial de trabajadores que devengan más del salario mínimo legal.

Asimismo, la población en general, requiere que se le garantice el bien común, que es el límite constitucional a la libertad económica y de empresa, acorde a lo dispuesto en el artículo 333 de la Constitución Política, y esto implica propiciar condiciones que permitan una vida digna y para ello, es indispensable la generación de ingresos que le permitan a los trabajadores sostener sus hogares y evitar que se ubiquen en condiciones de pobreza. El Congreso debe entonces expedir leyes encaminadas a garantizar estas condiciones dignas de vida a la población y el Gobierno debe expedir políticas públicas en el mismo sentido.

Es por ello que el legislativo debe tener presente que el salario, es una de las principales fuentes de ingresos familiares. La ausencia de ingresos salariales en las familias puede generar condiciones de vulnerabilidad y la pérdida del poder adquisitivo del salario, amplia la brecha existente generando mayor desigualdad salarial, problema que, según la OIT, debe ser combatido con políticas públicas y diversas estrategias en todo el mundo.

Recuérdese que, para combatir la pobreza, se debe más que subsidiar a la población vulnerable, se deben tomar medidas que permitan que la población genere ingresos sostenibles, que reduzcan los índices de pobreza intergeneracional y evitando que siga aumentando este índice, pues la pobreza, así como las deudas, se puede heredar. 
Adviértase que en el Informe de Salarios 2016-2017 emitido por la Organización Internacional del Trabajo (OIT), se menciona que es un objetivo trazado a nivel mundial, el garantizar a la población, trabajos decentes, buscando el crecimiento de los salarios y reduciendo la desigualdad salarial existente. Se resalta el siguiente aparte del informe:

"La Agenda 2030 de las Naciones Unidas para el Desarrollo Sostenible, incluyó el trabajo decente para todas las mujeres y los hombres, y la reducción de la desigualdad, entre los objetivos fundamentales de una nueva agenda política universal. Las cuestiones del crecimiento salarial y la desigualdad salarial ocupan un lugar preeminente en esta Agenda...La mejora de los salarios y las oportunidades de trabajo decente son esenciales para liberar a la economía mundial de la trampa en la que se encuentra" (OIT, 2017).

Por todo lo anterior, el Congreso de la República Colombiana debe cumplir con su obligación de legislar respecto al incremento anual de los salarios que superan el salario mínimo vital y móvil. Existe un Incumplimiento del Estado del deber de desarrollar jurídicamente el principio mínimo fundamental constitucional de movilidad salarial de los trabajadores del sector privado que devenguen por encima del salario mínimo legal mensual vigente, lo cual valida la hipótesis de que existe una ausencia por parte del Estado en el cumplimiento de sus deberes en relación con el desarrollo jurídico del principio constitucional de movilidad salarial de los trabajadores.

Agregaría a lo anterior, que las políticas públicas y la expedición de leyes y reformas legislativas, deben apuntarle a propiciar condiciones que permitan un desarrollo sostenible en el país, disminuir la gran desigualdad salarial existente y se combata a la pobreza. Una alternativa para hacerlo, es regulando el trabajo de tal forma, que se convierta en un trabajo decente y digno, para lo cual el gobierno colombiano debería trazarse objetivos como los siguientes:

1) Regulación del salario superior al mínimo: Se propone la expedición de una norma jurídica que establezca que todos los salarios del sector privado superiores al salario mínimo legal mensual vigente, se deberán incrementar por lo menos, con el porcentaje del índice de Precios al Consumidor (IPC) publicado por el Departamento Administrativo Nacional de Estadística (DANE) para el año inmediatamente anterior. Este reajuste o incremento, debe darse a partir del primer día calendario de cada año. La norma en mención, puede estar contenida en el Estatuto del Trabajo o en una Ley que modifique el Código Sustantivo del Trabajo o lo complemente.

Para el reajuste o incremento salarial, también se podrá tener en cuenta los demás aspectos señalados en el artículo 8 de la ley 278 de 1996, para la fijación del salario mínimo, sin olvidar que la empresa cumple una función social de la empresa y que existe una protección constitucional para el trabajo y el salario dignos y la movilidad salarial. 
2) Expedir el Estatuto del Trabajo y desarrollar en él, los principios mínimos en materia laboral, especialmente el de movilidad salarial.

Esto permitiría entre otros aspectos, garantizar seguridad jurídica, pues varios de estos principios mínimos, son desarrollados jurisprudencialmente por las Altas Cortes.

Un Estatuto como fuente formal de derecho, hará que las decisiones judiciales se deban ajustar a lo dispuesto en dicho Estatuto. Nótese que, en ausencia de normas, tanto los jueces como las partes en un proceso, "escogen" el precedente judicial que se logra "ajustar" como fundamento, a sus pretensiones o decisiones (en el caso de los jueces).

Respecto a los principios mínimos laborales, en ocasiones estos fundamentan acciones de tutela, acciones constitucionales que pueden ser resueltas por operadores judiciales que muchas veces no son especialistas o conocedores del área laboral y de seguridad social, es por ello, que la existencia de un Estatuto del Trabajo, facilitaría la labor judicial para la resolución de los pleitos judiciales, más aún, cuando se está frente a acciones de tutela que tiene términos de solo diez (10) días para su fallo.

De igual forma un Estatuto del Trabajo sería una fuente formal de observancia por los sujetos de la relación laboral que propendería por lograr que en Colombia los trabajos sean decentes, dignos y se equilibre la relación de trabajo.

3) Un crecimiento salarial sostenible, con empleos formales que tengan salarios dignos, que sean móviles y que sus montos permitan el ahorro, el pago de seguridad social, el consumo al sector productivo del país y el pago de impuestos al Estado, acorde a las obligaciones tributarias de cada persona. Todo lo anterior, contribuye, además, a la sostenibilidad de la inversión y a la productividad empresarial.

4) Reducción de la desigualdad salarial de los trabajadores en todos los sectores y géneros. Garantizar la igualdad de trato a los trabajadores.

5) Efectiva protección a desarrollo del derecho de asociación sindical, a la libertad sindical, al sindicalismo y a la Negociación Colectiva.

6) Sistema tributario más progresivo, donde se desgrave a los menos favorecidos y se tribute acorde a la capacidad económica revisando el tema de exenciones, regímenes especiales en materia fiscal y parafiscal.

7) Fomentar el Incremento de la formalidad y estabilidad en el empleo en Colombia, mediante regulación y controles procurando que la contratación no sea por cortos lapsos de tiempo cuando la realidad y la necesidad demuestran la vocación de permanencia de los empleos. 
8) Velar para que no exista un abuso de las figuras de tercerización laboral y de contratos de prestación de servicios y sancionar fuertemente a quienes comentan estos actos y con mayor severidad a los reincidentes.

9) Fortalecer y ampliar la cobertura de educación en todos los niveles que permita satisfacer las necesidades del sector productivo del país y de la población colombiana.

10) Fortalecimiento de las Instituciones del Estado y de los mecanismos de administración de justicia laboral, así como una mejora en la efectividad, celeridad y eficacia de los procedimientos para resolución de conflictos.

11) Promoción de empresas sostenibles que respeten la dignidad humana, el trabajo decente y la sostenibilidad del medio ambiente

12) Se reforme el sistema pensional para reducir el déficit y que más personas accedan a pensiones.

\section{CONCLUSIONES}

Luego de realizada la investigación propuesta, se logró explicar la movilidad salarial en el ordenamiento jurídico colombiano desde la teoría de la omisión legislativa. Para ello, se determinó la regulación existente respecto a la movilidad salarial en el sistema jurídico colombiano, se analizó la teoría de la omisión legislativa de Wessel y se estableció la relación que existe entre omisión legislativa y movilidad salarial en el ordenamiento jurídico colombiano, concluyendo los siguientes aspectos:

a) La relación existente entre la regulación de la movilidad salarial en Colombia y la teoría de la omisión legislativa de Wessel, es que, en el ordenamiento jurídico colombiano, respecto a movilidad salarial, existe una omisión legislativa que afecta a los trabajadores del sector privado de la economía, que devengan más de un salario mínimo mensual legal vigente, al ser estos, quienes no cuentan con normas que regulan la forma de hacer los incrementos anuales salariales.

b) La omisión legislativa existente respecto a movilidad salarial, vulnera principios fundamentales constitucionales, laborales, el derecho fundamental al trabajo digno y, además, desnaturaliza el carácter sinalagmático y conmutativo del contrato de trabajo, generando un enriquecimiento injustificado al Empleador con un empobrecimiento correlativo del trabajador, que podría afectar su mínimo vital y la vida en condiciones dignas y justas, tal como se planteó en la hipótesis de la investigación.

c) En el ordenamiento jurídico colombiano se advierte una omisión legislativa absoluta respecto a la expedición del Estatuto del Trabajo, pues en el artículo 53 de la Constitución Política de 1991, está contenido un mandato dirigido al Congreso de la República. En dicho 
Estatuto del Trabajo, se deberá desarrollar lo que se denominan "principios mínimos fundamentales para el trabajo", siendo uno de estos, el principio de remuneración móvil, o movilidad salarial.

d) Cuando se trata del fenómeno de inconstitucionalidad por omisión legislativa, también llamada omisión legislativa inconstitucional o simplemente conocida como omisión legislativa, el Congreso contradice la supremacía de la Constitución y los principios democráticos y valores fundamentales que están contenidos en la Carta Política y que requieren de un desarrollo legislativo para su materialización.

e) Respecto al fenómeno de las omisiones legislativas, la Corte Constitucional ha admitido su competencia para conocer de demandas de inconstitucionalidad por omisión legislativa relativa, concretamente, para proteger el derecho a la igualdad o el derecho de defensa, pero no admite competencia cuando se trata de omisión legislativa absoluta, siendo en este último caso, responsabilidad exclusiva del Congreso el cumplir con la obligación legislativa.

f) La existencia de la omisión legislativa respecto a la movilidad del salario de los trabajadores que devengan más de un salario mínimo mensual vigente, va en contra del principio constitucional de la dignidad del trabajo y del salario, y afecta también el carácter sinalagmático y conmutativo del contrato laboral.

g) La movilidad salarial en Colombia se regula de forma diferente para el sector público y para el sector privado. A los empleados públicos con relación legal y reglamentaria, anualmente, por decreto les fijan su incremento salarial anual, pero no ocurre de igual forma con los trabajadores que hacen parte del sector particular o privado.

Lo anterior contradice principios como el de movilidad salarial, de igualdad de trato, el principio que dice a igual trabajo igual salario, el principio de equidad, justicia social, solidaridad, bien común dignidad del salario y del trabajo.

Atenta además contra los valores y principios fundamentales para el Estado democrático y social de derecho colombiano enunciados en la Constitución Política.

h) Es necesario regular el tema de los reajustes salariales en aras de garantizar un salario digno, cumpliendo el principio constitucional de remuneración móvil o movilidad salarial, garantizando con ello que la totalidad de trabajadores del territorio colombiano tengan 
reajustes anuales sin que se pierda el salario el poder adquisitivo real, brindándose de esta manera una protección especial al trabajo como lo ordena la Constitución Política.

i) Es deber estatal dirigir la economía y garantizar un orden económico y socialmente justo, esto conlleva a que se deba regular la movilidad salarial de los trabajadores que devengan más de un salario mínimo, esto acorde a la Constitución Política, a la normatividad internacionales aplicable y a la jurisprudencia nacional.

j) Una remuneración móvil además de incrementar el salario nominal debe apuntarle al incremento del salario real, para que las personas no pierdan realmente el poder adquisitivo, puedan satisfacer las necesidades básicas propias y las de sus familias, se incremente el consumo y además los salarios, participen en mayor medida en el PIB.

k) La tendencia mundial de los salarios acorde a la OIT y a la ONU es la de aplicar políticas salariales sostenibles, que atajen el estancamiento de estos, aumenten los niveles de remuneración de los millones de trabajadores y trabajadoras pobres del mundo, aseguren una distribución justa, reduzcan las excesivas desigualdades de los salarios y de la renta, y refuercen el consumo como pilar fundamental de una economía sostenible.

I) Para conjurar la omisión legislativa se propone la expedición del Estatuto del Trabajo y la regulación del principio mínimo fundamental del trabajo de movilidad salarial. Respecto a la movilidad salarial del salario superior al mínimo legal mensual vigente, se propone que se garantice que los trabajadores que devenguen este tipo de salarios y que estén en el sector privado de la economía, por lo menos, tengan derecho a un incremento o porcentaje de aumento equivalente al IPC certificado por el DANE, en el año inmediatamente anterior, para que, de esta manera, el principio constitucional de movilidad salarial, no sea ineficaz para dichos trabajadores.

\section{REFERENCIAS BIBLIOGRÁFICAS}

ACOBERRO, R. (22 de junio de 2017). Filosofia i pensament. Obtenido de Filosofia i pensament: http://www.alcoberro.info/web/V1/rawls.htm

ALEXY, R. (1993) Teoría de los Derechos Fundamentales. Madrid, Centro de estudios Políticos y Constitucionales. Segunda Edición en español.

ALEXY, R. (2014) Teoría de los derechos fundamentales. Madríd España. Centro de Estudios Políticos y Constitucionales. 
Araque, F. y Suárez, O. (2017). Equidad Ética-Jurídica de la Ciencia, para la Emancipación del Conocimiento y los Saberes. Jurídicas CUC, vol. 13, no. 1, pp. 97-120. DOI: http://dx.doi.org/10.17981/juridcuc.13.1.2017.5

GALEANO, M. Amaya (Abril de 2012). Gestión Moderna de Salarios e Incentivos. Bussiness Process Management (BPM). Bogotá (Colombia) Colección Desarrollo Empresarial. Escuela Colombiana de Ingeniería Julio Garavito.

ABELA, J. Andréu (2000). Las técnicas de análisis de contenido: una revisión actualizada. Fundación Centro Estudios Andaluces, 1-34.

ARANGO, R. (2012) El concepto de derechos sociales Fundamentales, Legis Editores S.A. Segunda Edición en Español.

ARDILA, J. y Bedoya Y. (2014). Tesis de Grado. Movilidad Salarial Coyuntura legal y Jurisprudencial. Universidad San Buenaventura. (Medellín).

BARONA Betancourt, R. (2010). Principios del derecho laboral en el sistema jurídico colombiano. Criterio jurídico garantista. Año 2 (No. 2) - Enero-Junio, 252- 264.

BARRÍA, C. (12 de octubre de 2017). BBC. Recuperado el 25 de 05 de 2018, de:

http://www.bbc.com/mundo/noticias-41571745

BAZÁN V. (2007). Neoconstitucionalismo e inconstitucionalidad por omisión. Revista Derecho del Estado.

BIDART Campos, Germán. Algunas reflexiones sobre las omisiones inconstitucionales. En Inconstitucionalidad por omisión. VíCTOR BAZÁN Coordinador Editorial Temis. Bogotá. 1997. Pág. 14 y ss.

BILBAO, Andrés. (1993). Obreros y ciudadanos. La destrucción de la clase obrera. Editorial Trotta, Madrid, 1993. Páginas 39-76. ISBN 9788487699627.

CALDERÓN Ortega, M. A. (Enero-Junio de 2014). Estado de Cosas Incostitucional por omisión en la expedición del estatuto del trabajo en Colombia. Revista Academia \& Derecho. Universidad Libre Seccional Cúcuta (8), 71-97. Obtenido de:

http://www.unilibrecucuta.edu.co/ojs/index.php/derecho/article/view/80/74 
CAMPOS, G. B. (1997). Algunas reflexiones sobre las omisiones inconstitucionales. Bogotá: Temis.

CANITROT, A. (1983). El Salario Real y la Restricción Externa de la Economía. Desarrollo Económico Volumen 23 No. 91. Instituto de Desarrollo Económico.

CAÑON, L. (2010) Una visión integral de la seguridad social. Bogotá, Colombia: Departamento de publicaciones de la Universidad Externado de Colombia.

CATAÑO M., J. F. (1995). La plusvalía marxista: ¿reformulación clásica o monetaria? En Cuadernos de economía (Vol. 14, págs. 24-52). Universidad Nacional de Colombia - Sede Bogotá - Facultad de Ciencias Económicas - Escuela de Economía. Recuperado el 23 de junio de 2018, de http://bdigital.unal.edu.co/18077/1/13818-63858-1-PB.pdf

CASAL H., Jesús M. La protección de la Constitución frente a las omisiones legislativas. Anuario de derechos constitucionales latinoamericano. Montevideo Honrad Adenmauer Stiftung, 2003. P. 50.

CARRILLO, Flórez, Perona (2018) Constitucionalismo y Filosofía Constitucional, Cuadernos de Filosofía del Derecho y Teoría Constitucional. Ediciones Nueva Jurídica, Bogotá, Colombia.

CIFUENTES Muñoz E. (2002). Jurisdicción Constitucional en Colombia. Revista lus et Praxis.

CIA World Factbook. (s.f.). Index Mundi. Recuperado el 18 de junio de 2018, de https://www.indexmundi.com/g/r.aspx?v=25\&l=es

CÓDIGO SUSTANTIVO DEL TRABAJO Y CÓDIGO PROCESAL DEL TRABAJO Y LA SEGURIDAD SOCIAL [2016]. (1951). Legis Editores.

CÓDIGO SUSTANTIVO DEL TRABAJO Y CÓDIGO PROCESAL DEL TRABAJO Y LA SEGURIDAD SOCIAL. (1951[2018]). 41 Edición. Legis Editores.

CÓDIGO SUSTANTIVO Y PROCESAL DEL TRABAJO, (1951[2010]). Grupo Editorial Nueva Legislación Ltda., Bogotá. D.C., Colombia. ISBN 978-958-8371-30-6

COLOMBIA, CORTE CONSTITUCIONAL. (13 de marzo de 1995). Sentencia T-102. M.P. Dr. Alejandro Martínez Caballero. 
Paola Stella Hernández Martelo

COLOMBIA, CORTE CONSTITUCIONAL. (7 de diciembre de 1995). Sentencia SU 599. M.P. Dr. Fabio Morón Díaz.

COLOMBIA, CORTE CONSTITUCIONAL. (23 de agosto de 1996). Sentencia T-401. M.P. Dr. Vladimiro Naranjo Mesa

COLOMBIA, CORTE CONSTITUCIONAL (16 de octubre de1996). Sentencia C-543. M.P. Dr. Carlos Gaviria Díaz.

COLOMBIA, CORTE CONSTITUCIONAL (20 de octubre de 1999) Sentencia C- 815. M.P. Dr. José Gregorio Hernández Galindo.

COLOMBIA, CORTE CONSTITUCIONAL (9 de diciembre de 1999) Sentencia SU 995. M.P. Dr. Carlos Gaviria Díaz.

COLOMBIA, CORTE CONSTITUCIONAL. (23 de octubre de 2000) Sentencia C-1433. M.P. Dr. Antonio Barrera Carbonell

COLOMBIA, CORTE CONSTITUCIONAL. (21 de noviembre de 2000) Sentencia C-1549. M.P. (E) Dra. Martha Victoria Sáchica Méndez.

COLOMBIA, CORTE CONSTITUCIONAL. (7-de noviembre de 2012) Sentencia C-911. M.P. Dr. Mauricio González Cuervo.

COLOMBIA, CORTE SUPREMA DE JUSTICIA, SALA DE CASACIÓN LABORAL. (5 de noviembre de 1999) Sentencia SL12213. M.P. Luis Gonzalo Toro Correa.

COLOMBIA, CORTE SUPREMA DE JUSTICIA, SALA DE CASACIÓN LABORAL. (13 de marzo de 2001). Sentencia SL15406, 2001. M.P. José Roberto Herrera Vergara

COLOMBIA, CORTE SUPREMA DE JUSTICIA, SALA DE CASACIÓN LABORAL. (20 de marzo de 2002). Sentencia SL17164, 2002) M.P. Fernando Vásquez Botero\}

CONSTITUCIÓN POLÍTICA DE COLOMBIA [Const.] (1991 [2013]). Bogotá: Legis Editores S.A.

CONSTITUCIÓN POLÍTICA DE COLOMBIA [Const.] (1991 [2016]). Bogotá: Legis Editores S.A. Bogotá. Legis Editores S.A. 35ㄹ, Edición. 
COMISIÓN DE EXPERTOS DE LA OIT - Conferencia Internacional del Trabajo 91a Reunión. (2003). Informe III (parte IB). Estudio general de las memorias relativas al Convenio (núm. 95). Informe de la Comisión de Expertos en Aplicación de Convenios. Francia: Primera Edición.

CONTI, A. (2008). Los principios del derecho del trabajo y su dimensión democrática. En U. E. Colombia, Manual de Derecho Laboral (pág. 863). Bogotá: Departamento de Publicaciones de la Universidad Externado de Colombia.

CHAVARRO, J. (2011) Sistema de seguridad social integral. Bogotá, Colombia. Grupo editorial nueva legislación.

DANE. (2014). Comportamiento del mercado laboral por sexo. Bogotá.

DANE. (2018). Colombia, Indice de Precios al Consumidor (IPC). Variaciones porcentuales 20032008. Bogotá.

DeConceptos.com (s.f.). DeConceptos.com. Recuperado el 2 de junio de 2018, de: https://deconceptos.com/ciencias-juridicas/salario

DEPARTAMENTO ADMINISTRATIVO DE LA FUNCIÓN PÚBLICA. (19 de Julio de 2017). Decreto 1250. Bogotá, Colombia .

DEPARTAMENTO ADMINISTRATIVO DE LA FUNCIÓN PÚBLICA. (s.f.). Función Pública. (G. d. Colombia, Productor) Recuperado el 25 de 6 de 2018, de:

http://www.funcionpublica.gov.co/reajuste-salarial

DíAZ Gamboa, L. B. (2009). La Inconstitucionalidad por Omisión. Necesidad de reconocimiento de la figura en Colombia. Criterio Jurídico Garantistaa, Pag. 162- 191. Obtenido de http://revistas.fuac.edu.co/index.php/criteriojuridicogarantista/article/view/301

ECONOMÍA FINANZAS. (s.f.). Economía Finanzas. Recuperado el 3 de Junio de 2018, de https://www.economiafinanzas.com/equipo-editorial/

ENCICLOPEDIA FINANCIERA. (s.f.). Enciclopedia financiera. Obtenido de: www.enciclopediafinanciera.com/deficion-sector-privado.html

ENCICLOPEDIA JURÍDICA. (2014). Recuperado el 22 de 06 de 2017, de http://www.enciclopediajuridica.biz14.com/d/enriquecimiento-sin-causa/enriquecimiento-sin-causa.htm 
FERNANDEZ Rodriguez, J. J. (1998). La Inconstitucionalidad por Omisión: Teoría General Derecho Comparado, el caso español. Civitas.

FERRARO, J. (1978). La teoría valor-trabajo según Marx y Santo Tomás y su aplicación en las relaciones de producción capitalistas. Revista de Filosofía Diánoia, XXIV(24), 201-219. Recuperado el 20 de Junio de 2018, de:

http://dianoia.filosoficas.unam.mx/index.php/contenido/n-meros-anteriores/24/la-teor-avalortrabajo-seg-n-marx-y-santo-tom-s-y-su-aplicaci-n-en-las-relaciones-de-producci-n-capitalistas/

FERREIRA, F. H., Julian, M., Rigolini, J., López Calva, L. F., Lugo, M. A., \& Vakis, R. (2013). (B. Mundial, Ed.) doi:10.1596/978-0-8213-9752-7

GARZÓN Buenaventura, E. F. (20 de Diciembre de 2014). La inconstitucionalidad por omisión: Una revisión Jurídica. Dixi, 16(20), 29-36. Recuperado el 20 de 12 de 2017, de Doi: http://dx.doi.org/10.16925/

GIRALDO Ángel, J. (1992). Metodología y técnica de la investigación jurídica . Bogotá: Ediciones librería del profesional.

GOYES Moren, I- \& Hidalgo Oviedo M. (2012). ¿Los principios del derecho laboral y la seguridad social dinamizan la jurisprudencia constitucional en Colombia? Revista Entramado.

GUERRERO Figueroa, G. (2004). Sección Primera. Generalidades sobre la evolución y reglamentación del trabajo. En G. Guerrero Figueroa, El trabajo y su reglamentación en América. (págs. 17-25). Bogotá, D.C.: Leyer.

HERNÁNDEZ Sampieri, R., Fernández Collado, C., \& Baptista Lucio, M. (2010). Metodología de la investigación. México D.F.: McGraw Hill.

KELSEN, Hans. - La garantía Jurisdiccional de la Constitución\|. En Escritos sobre la Democracia y el Socialismo. Selección y Presentación de Juan Ruiz Manero. Editorial Debate Madrid.

KELSEN, Hans. ¿Quién debe ser el defensor de la Constitución?, Madrid, Editorial Tecnos, 1995.

LÓPEZ, D. (2007) El derecho de los jueces. Bogotá, Colombia. Legis S. A.

LÓPEZ, H., \& Lasso, F. (2008). Salario mínimo, salario medio y empleo asalariado privado en Colombia. Un estudio exploratorio sobre la evasión al mínimo legal. Borradores de la Econonomía. No. 484. Medellín., Colombia.: Banco de la República. 
MarbuRY vs. Madison. De la Corte Suprema de Estados Unidos de América. (24 de febrero de 1803). Traducción profesor Ignacio Fernández Sarasola.

MINISTERIO DEL INTERIOR. (2010). Código Sustantivo y Procesal del Trabajo (Primera ed.). (Grupo Editorial Nueva Legislación Ltda., Ed.) Bogotá D.C., Colombia.

MONTERROSA, H. (16 de noviembre de 2017). Según el Banco Mundial, Colombia es el segundo país más desigual de América Latina. La República.Recuperado el 25 de 6 de 2018, de:

https://www.larepublica.co/economia/segun-el-banco-mundial-colombia-es el-segundo-paismas-desigual-de-america-latina-2570469

NACIONES UNIDAS (1966). Pacto Internacional de Derechos Civiles y Políticos. Recuperado el 1 de mayo de 2018, de https://www.ohchr.org/SP/Professionallnterest/Pages/CCPR.aspx

NACIONES UNIDAS (1966). Pacto Internacional de Derechos Económicos y Sociales y Culturales. Recuperado el 1 de mayo de 2018, de:

https://www.ohchr.org/sp/Professionallnterest/Pages/CESCR.aspx

NOGUEIRA Alcalá, Humberto. Consideraciones sobre las sentencias de los tribunales constitucionales y sus efectos en América del Sur. Revista lus et Praxis 10. 2004. Págs. 154-155.

OEA (1969). Convención Americana sobre Derechos Humanos (Pacto de San José). Recuperado el 1 de mayo de 2018, de:

https://www.oas.org/dil/esp/tratados b32 convencion americana sobre derechos humanos $\underline{\text { htm }}$

OECD. (2018). Average wages. Recuperado el 2 de Junio de 2018, de OECD DATA: https://data.oecd.org/earnwage/average-wages.htm

OIT. (2017). OIT. Ginebra. Informe mundial sobre salarios 2016/2017: Desigualdades salariales en el lugar de trabajo. Recuperado el 20 de junio de 2018, de:

http://www.ilo.org/global/publications/books/WCMS 541632/lang--es/index.htm

OIT, C026 - Convenio sobre los métodos para la fijación de salarios mínimos, 1928 (núm. 26). Ratificado el 20 junio 1933. Recuperado el 2 de junio de 2016, de:

http://www.ilo.org/dyn/normlex/es/f?p=NORMLEXPUB:12100:0::NO::P12100 ILO CODE:C026 
OIT, C095 - Convenio sobre la protección del salario, 1949 (núm. 95). Ratificado el 7 junio 1963. Recuperado el 2 de junio de 2016, de:

http://www.ilo.org/dyn/normlex/es/f?p=NORMLEXPUB:12100:0::NO:12100:P12100 INSTRUM ENT ID:312240:NO

OIT, C099 - Convenio sobre los métodos para la fijación de salarios mínimos (agricultura), 1951 (núm. 99). Recuperado el 2 de junio de 2016, de:

http://www.ilo.org/dyn/hormlex/es/f?p=NORMLEXPUB:12100:0::NO:12100:P12100 INSTRUM ENT ID:312244:NO

OIT, C100 - Convenio sobre igualdad de remuneración, 1951 (núm. 100). Recuperado el 2 de junio de 2016, de:

http://www.ilo.org/dyn/normlex/es/f?p=NORMLEXPUB:12100:0::NO:12100:P12100 ILO CODE $:$ :C100

OIT, C111 - Convenio Internacional del Trabajo 111, 1958 (núm. 111) Recuperado el 2 de junio de 2016, de:

http://www.ilo.org/dyn/hormlex/es/f?p=NORMLEXPUB:12100:0::NO:12100:P12100 INSTRUM ENT ID:312156:NO

OIT, C144 - Convenio sobre la consulta tripartita (normas internacionales del trabajo) para promover la aplicación de las normas internacionales del trabajo.144, 1976 (núm. 144) Recuperado el 2 de junio de 2016, de

OIT, R135 - Recomendación sobre fijación de Salarios Mínimos, 1970 (núm. 135). Recuperado el 2 de junio de 2016, de:

http://www.ilo.org/dyn/normlex/es/f?p=NORMLEXPUB:12100:0::NO:12100:P12100 INSTRUM ENT ID:312280:NO

OIT, R135 - Recomendación sobre fijación de Salarios Mínimos, 1970 (núm. 135). Recuperado el 2 de junio de 2016, de:

http://www.ilo.org/dyn/hormlex/es/f?p=NORMLEXPUB:12100:0::NO:12100:P12100 INSTRUM ENT ID:312473:NO

ORGANIZACIÓN INTERNACIONAL DEL TRABAJO [OIT]. (2017). Resumen del Informe Mundial sobre Salarios 2016-2017: Desigualdades salariales en el lugar de trabajo. Ginebra. Recuperado el 20 de Junio de 2018, de: http://www.ilo.org/global/research/global-reports/global-wagereport/2016/WCMS 537989/lang--es/index.htm 
ORGANIZACIÓN INTERNACIONAL DEL TRABAJO [OIT]. (s.f.). Salarios.Organización Internacional del Trabajo. Recuperado el 10 de Junio de 2018, de:

http://www.ilo.org/global/topics/wages/lang--es/index.htm

ORTEGA, J. R. (Marzo de 2002). El salario: doctrina, normatividad, OIT, jurisprudencia. Bogotá, Colombia: Editorial Leyer.

PALACIO, Germán (1994). El Trabajo en los Noventa: Rupturas y Conflictos. Artículo en: "Flexibilidad Laboral y Neoliberalismo". Universidad Nacional de Colombia.Facultad de Derecho, Ciencias Políticas y Sociales. 1a edición. Santafé de Bogotá. Páginas 72 a 83.

PALOMEQUE, L. (2013). Proporcionalidad y eficacia de los Derechos Fundamentales. Primera edición. Editorial Buena Semilla. Bogotá.

PÉREZ Saínz, J. P. (2003). Globalización riesgo y empleabilidad, algunas hipótesis. Nueva Sociedad 184. Págs. 68-85.

PETRO González, Ingrid Regina (2016). El juez en el Neoconstitucionalismo y su papel en el Sistema de Control Difuso de Constitucionalidad en Colombia. Revista Jurídica Mario Alario D’Filippo, VIII (16), pág 125-134.

PIÑEROS, K. B. (24 de Marzo de 2017). Colombia, el segundo país con mayor pobreza de la región. La República. Recuperado el 25 de junio de 2018, de:

https://www.larepublica.co/globoeconomia/colombia-el-segundo-con-mayor-pobrezaextremaen-la-region-2487706

PORTAFOlIO. (20 de 11 de 2017). Así se ha definido el salario mínimo en los últimos años. Portafolio. Recuperado el 26 de abril de 2018, de: http://www.portafolio.co/economia/como-seha-definido-el-salario-minimo-en-los-ultimos-anos-511812

PULZO. (1 de febrero de 2018). PULZO. Recuperado el 25 de 05 de 2018, de:

https://www.pulzo.com/economia/colombia-entre-paises-desiguales-mundo-PP432012

QUINCHE, M. El precedente judicial y sus reglas. Bogotá, Colombia. Legis S. A.

RAWLS, J. (1997). (M. F. Económica, Ed.) 
Paola Stella Hernández Martelo

REAL ACADEMIA DE LA LENGUA. (3 de octubre de 2014). Real Academia de la Lengua Española. Recuperado el 3 de diciembre de 2016, de Real Academia de la Lengua Española: http://dle.rae.es/?id=3uQPd00

ROBLEDO A. (2010) La interpretación Democrática en el Liberalismo Igualitario de Jhon Rawls. En Revista Jurídica Mario Alario D’Filipo. Universidad de Cartagena. Volumen 1 Revista No. 4.

RODRIGUEZ, C. (2004). La Justicia Laboral. Ediciones Uniandes. Facultad de Derecho. Centro de Investigaciones Sociojurídicas. El caleidoscopio de las Justicias en Colombia. Análisis sociojurídico Tomo I (pp. 615-682). Colombia.

SANTA María, M., Prada, C. F., \& Mujica, A. V. (2009). Oportunidades, desafios y barreras de la Movilidad den Colombia: Reflexiones para la población en pobreza extrema y moderada. Fedesarrollo. Centro de Investigación Económica y Social.

SANTOS, F. I. (2011). Capítulo Primero. Omisión Legislativa. Consideraciones Generales. En I. S. Flórez, Omisión Legislativa en Materia Tributaria. El caso de México (págs. 1- 39). México: Universidad Nacional Autónoma de México.

SANTOS, F. I. (2011). La omisión legislativa en maria tributaria. El caso de México. México: Instituto de Investigaciones Jurídicas UNAM. 